\title{
Excess Molar Enthalpies of Mixtures of Acetylene Tetrachloride with Dimethylsulfoxide, Acetone, Acetonitrile and N-Dibutyl Ether at $303.15 \mathrm{~K}$
}

\author{
Atri D. Tripathi* and Shalini Choudhary
}

Department of Chemistry, College of Engineering, Teerthankar Mahaveer University, Moradabad 244001, India

\begin{abstract}
The Excess molar enthalpies have been determined for binary liquid mixtures of acetylene tetrachloride $\left(\mathrm{CHCl}_{2} \mathrm{CHCl}_{2}\right)$ (ATC) with dimethylsulfoxide, acetone, acetonitrile and n-dibutyl ether at the temperature $303.15 \mathrm{~K}$ by microcalorimetry.

The excess molar enthalpies are negative for all the mixtures over the whole composition range. The results were fitted with the Redlich-Kister equation by means of the least square method. The values of $\mathrm{H}^{\mathrm{E}}$ decrease in the order: Dimethylsulphoxide $>$ acetone>acetonitrile $>$ dibutyl ether. The same decreasing trend was observed for calculated hydrogen bond energies of these systems. These results indicate the existence of specific interactions between all these components.
\end{abstract}

Keywords: Excess molar enthalpy, acetylene tetrachloride, acetone, microcalorimetry, hydrogen bonding.

\section{INTRODUCTION}

As a part of our ongoing efforts to obtaining thermodynamic and physicochemical quantities on organic liquid mixtures [1-6] we report here excess enthalpies of acetylene tetrachloride $\left(\mathrm{CHCl}_{2} \mathrm{CHCl}_{2}\right)$ (ATC) with dimethylsulfoxide, acetone, acetonitrile and n-dibutyl ether at $303.15 \mathrm{~K}$. Binary systems of $\mathrm{CHCl}_{2} \mathrm{CHCl}_{2}$ with all these compounds are of considerable interest due to occurrence of specific interactions between these components in the liquid state. This is due to the occurrence of four $\mathrm{Cl}$ atoms and two $\mathrm{H}$ atoms in $\mathrm{CHCl}_{2} \mathrm{CHCl}_{2}$, which can therefore take action as $\sigma$-acceptors towards, and be concerned in the hydrogen bond construction with dimethylsulfoxide, acetone, acetonitrile and n-dibutyl ether. Latter compounds will operate as n-donors. $\mathrm{CHCl}_{2} \mathrm{CHCl}_{2}$ has two alike proton donors and can therefore form dissimilar type of complexes with the latter compounds. With the help of an NMR study McClellan and Nicksic [7] concluded that $\mathrm{CHCl}_{2} \mathrm{CHCl}_{2}$ is self-associated in the liquid state, while Tripathi [3], from the dielectric property measurement showed that it formed a 1: 1 complex with acetone. A literature survey exposed that broad studies on such systems have not been conceded out to date. The experimental data have also been interpreted in this paper.

The study of acetylene tetrachloride $\left(\mathrm{CHCl}_{2} \mathrm{CHCl}_{2}\right)$ (ATC) with dimethylsulfoxide, acetone, acetonitrile and

*Address correspondence to this author at the Department of Chemistry, College of Engineering, Teerthankar Mahaveer University, Moradabad 244001, India; Tel: +919458444596; E-mail: atrideo@rediffmail.com n-dibutyl ether is of interest, not only because the compounds are of industrial importance, but also because their interactions are pronounced, making them better solvents and also used in day-to-day life.

ATC is a chlorinated derivative of ethane. It contains the maximum solvent power of any chlorinated hydrocarbon. As a refrigerant, it is marketed under the name R-130. It was extensively used as a solvent and as an intermediate in the business production of trichloroethylene, tetrachloroethylene, and 1, 2dichloroethylene. However, ATC is no longer used much in the United States due to concerns about its toxicity. Dimethyl sulfoxide (DMSO) is an organosulfur compound with the formula $\left(\mathrm{CH}_{3}\right)_{2} \mathrm{SO}$. This dull liquid is a significant polar aprotic solvent that dissolves both polar and nonpolar compounds and is miscible in an extensive range of organic solvents as well as water. Acetone (systematically named propanone) is the organic compound with the formula $\left(\mathrm{CH}_{3}\right)_{2} \mathrm{CO}$. It is a dreary, mobile, burnable liquid, and is the simplest ketone.

Acetone is mixed with water and acts as an essential solvent in its own right, typically for cleaning purposes in the laboratory. Acetone is formed and disposed of in the human body through normal katabolic or anabolic mechanism. It is normally available in blood and urine. Acetonitrile is the chemical compound with the formula $\mathrm{CH}_{3} \mathrm{CN}$. This colorless liquid is the simplest organic nitrile (hydrogen cyanide is a simpler nitrile, but the cyanide anion is not classed as organic). It is created as a consequence of acrylonitrile manufacture and used as a polar aprotic 
solvent in organic synthesis and in the purification of butadiene. In the laboratory, it is used as a mediumpolarity solvent that is miscible with water and range of organic solvents, but not saturated hydrocarbons. It has a convenient liquid range and a high dielectric constant of 38.8. With a dipole moment of $3.92 \mathrm{D}$, acetonitrile dissolves a wide range of ionic and nonpolar compounds and is useful as a mobile phase in HPLC and LC-MS. The N-C-C skeleton is linear with a short C-N distance of $1.16 \AA$. Dibutyl ether is a chemical compound belonging to the ether family with the molecular formula of $\mathrm{C}_{8} \mathrm{H}_{18} \mathrm{O}$. It is colorless, volatile, and flammable liquid and has peculiar ethereal smell.

Liquid dibutyl ether is lighter than water. Alternatively, the vapor is heavier than air. It is not soluble in water, but it is soluble in acetone and many other organic solvents. Due to this property, dibutyl ether is used as solvent in different chemical reactions.

\section{EXPERIMENTAL}

Acetylene tetrachloride $\left(\mathrm{CHCl}_{2} \mathrm{CHCl}_{2}\right)$, dimethylsulfoxide and acetone (all Analar grade) were fractionally distilled and only the middle portion of compound was used for taking measurements. Acetonitrile (B.D.H.) and acetone (A.R.) were dried over recently activated molecular sieves $4 \mathrm{~A}$ before use. Minimum purity of chemicals were $99.0 \mathrm{~mol} \%$ as determined by GLC.

\subsection{Method}

A heat flux micro calorimeter [5] (C-80 model supplied from Setaram, France) was used for taking measurements on excess molar enthalpies, $H^{E}$, the temperature was restricted within $\pm 0.001 \mathrm{~K}$. Preparation of the solutions was done by mass. Accuracy of mole fractions is \pm 0.0001 . The trustworthiness of the instrument was earlier checked by measuring $\mathrm{H}^{\mathrm{E}}$ for systems of cyclohexane + hexane at $T=298.15 \mathrm{~K}$ as given elsewhere [1]. At equimolar composition i.e.at $\mathrm{x}_{1}=0.5$, the deviation of present work is $0.5 \%$ whereas about $1 \%$ in the mean deviations of the excess enthalpy is estimated.

\section{RESULTS AND DISCUSSIONS}

The experimental data for excess enthalpies, $\mathrm{H}^{\mathrm{E}}$ at the temperature $T=303.15 \mathrm{~K}$ for the all binary mixtures are given in Table 1. The obtained results were fitted by least squares to the equation:
Table 1: Excess Enthalpies of Acetylene Tetrachloride $\left(\mathrm{CHCl}_{2} \mathrm{CHCl}_{2}\right)$ (1) + Dimethylsulphoxide (2)+Acetone (2), + Acetonitrile (2), and + Dibutylether (2) at $303.15 \mathrm{~K}$

\begin{tabular}{|c|c|}
\hline $\mathbf{X}_{1}$ & $\mathrm{H}^{\mathrm{E}} /\left(\mathrm{J}^{\mathrm{mol}} \mathrm{mol}^{-1}\right)$ \\
\hline $\mathrm{CHCl}_{2} \mathrm{CHCl}_{2}(1)$ & +dimethylsulphoxide (2) \\
\hline 0.0762 & -676 \\
\hline 0.1234 & -1071 \\
\hline 0.1945 & -1751 \\
\hline 0.4111 & -3086 \\
\hline 0.4445 & -3189 \\
\hline 0.5887 & -3187 \\
\hline 0.7112 & -2738 \\
\hline 0.8557 & -1659 \\
\hline 0.9555 & -615 \\
\hline $\mathrm{CHCl}_{2} \mathrm{CHCl}_{2}(1)$ & + acetone (2) \\
\hline 0.0678 & -415 \\
\hline 0.1123 & -698 \\
\hline 0.2314 & -1367 \\
\hline 0.2556 & -1478 \\
\hline 0.3567 & -1875 \\
\hline 0.4515 & -2092 \\
\hline 0.5818 & -2119 \\
\hline 0.7012 & -1899 \\
\hline 0.7995 & -1523 \\
\hline 0.8999 & -919 \\
\hline 0.9223 & -748 \\
\hline $\mathrm{CHCl}_{2} \mathrm{CHCl}_{2}(1)$ & + acetonitrile (2) \\
\hline 0.0654 & -267 \\
\hline 0.0978 & -389 \\
\hline 0.1098 & -432 \\
\hline 0.1567 & -587 \\
\hline 0.2113 & -776 \\
\hline 0.2578 & -899 \\
\hline 0.2888 & -992 \\
\hline 0.4104 & -1234 \\
\hline 0.4987 & -1324 \\
\hline 0.5253 & -1323 \\
\hline 0.6238 & -1276 \\
\hline 0.7176 & -1104 \\
\hline 0.7987 & -843 \\
\hline 0.8446 & -689 \\
\hline 0.9805 & -98 \\
\hline $\mathrm{CHCl}_{2} \mathrm{CHCl}_{2}(1)$ & + dibutyl ether (2) \\
\hline 0.1042 & -421 \\
\hline 0.2143 & -714 \\
\hline 0.2596 & -811 \\
\hline 0.3224 & -925 \\
\hline 0.3654 & -969 \\
\hline 0.4478 & -1013 \\
\hline 0.578 & -967 \\
\hline 0.6234 & -911 \\
\hline 0.7082 & -772 \\
\hline 0.8456 & -434 \\
\hline 0.9387 & -171 \\
\hline
\end{tabular}




$$
\mathrm{H}^{\mathrm{E}} /\left(\mathrm{J} \cdot \mathrm{mol}^{-1}\right)=\mathrm{x}_{1} \mathrm{x}_{2} \sum_{\mathrm{i}=0}^{\mathrm{m}} \mathrm{A}_{\mathrm{i}}\left(\mathrm{x}_{1}-\mathrm{x}_{2}\right)^{\mathrm{i}}
$$

where $x_{1}$ refers to the mole fraction of $\mathrm{CHCl}_{2} \mathrm{CHCl}_{2}$. The fitting constants and the standard deviations, $\sigma$, are summarized in Table 2. Following equation has been used for the calculation of the standard deviations, $\sigma$,

$\sigma=\left[\Sigma\left(H^{E}-H_{\text {calc }}^{E}\right)^{2} /(m-n)\right]^{1 / 2}$

where $\mathrm{H}^{\mathrm{E}}$ refers the experimental values of excess enthalpy and $\mathrm{H}^{\mathrm{E}}$ calc calculated excess enthalpy which can be obtained by means of equation (1), experimental data is denoted by $m$ whereas $n$ is number of constants characteristic of a binary system. Graphical presentation of $\mathrm{H}^{\mathrm{E}}$ vs. mole fraction $\left(\mathrm{x}_{1}\right)$ is plotted in Figure 1.

The values of excess enthalpy outcome from the distraction of interactions between similar molecules and the introduction of new connections between dissimilar molecules [8].

All the binary systems show negative values of $\mathrm{H}^{\mathrm{E}}$. The extent of $\mathrm{H}^{\mathrm{E}}$ for the current mixtures are ascribed to the net effect of +ve and -ve donations due to the rupture of bonds or interactions between like molecules, and also due to the possibility of new bond creation e.g. hydrogen bonds between the unlike molecules. The negative values of excess enthalpy

Table 2: Least Squares Coefficients of Eq 1 for the Excess Molar Enthalpies, and the Standard Deviations, $\sigma$, of

\begin{tabular}{|c|c|c|c|c|c|}
\hline System & AO & A1 & A2 & A3 & $\sigma /\left(\mathrm{J} \mathrm{mol}^{1}\right)$ \\
\hline $\mathrm{CH}_{2} \mathrm{Cl}_{2} \mathrm{CH}_{2} \mathrm{Cl}_{2}(1)+\mathrm{DMSO}(2)$ & -13039.9 & -1060 & 2039 & -2235 & 19.42 \\
\hline $\mathrm{CH}_{2} \mathrm{Cl}_{2} \mathrm{CH}_{2} \mathrm{Cl}_{2}(1)+$ acetone (2) & -8530 & -1126 & -94.42 & -1517 & 7.80 \\
\hline $\mathrm{CH}_{2} \mathrm{Cl}_{2} \mathrm{CH}_{2} \mathrm{Cl}_{2}(1)+$ acetonitrile (2) & -5294 & -836.7 & 933 & 681 & 7.04 \\
\hline $\mathrm{CH}_{2} \mathrm{Cl}_{2} \mathrm{CH}_{2} \mathrm{Cl}_{2}(1)+$ dibutylether (2) & -4043 & 516.5 & 395.8 & 472.5 & 6.28 \\
\hline
\end{tabular}
Acetylene Tetrachloride $\left(\mathrm{CH}_{2} \mathrm{Cl}_{2} \mathrm{CH}_{2} \mathrm{Cl}_{2}\right)$ (1) + Dimethylsulphoxide (2)+Acetone (2), + Acetonitrile (2), and +Dibutylether (2) at $303.15 \mathrm{~K}$

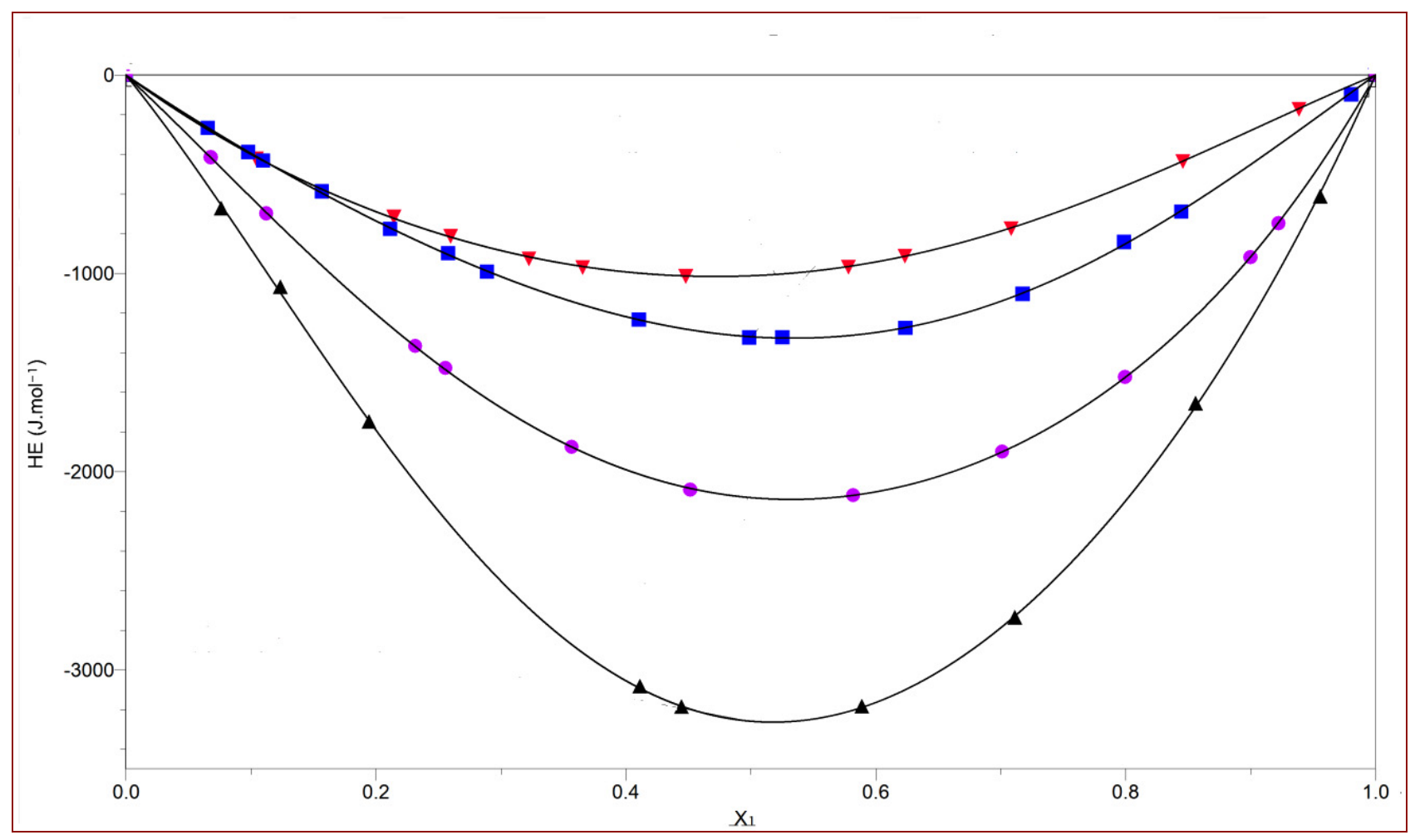

Figure 1: Excess molar enthalpies of binary liquid mixtures of $\mathrm{x}_{1}$ of Acetylene tetrachloride $\left(\mathrm{CH}_{2} \mathrm{Cl}_{2} \mathrm{CH}_{2} \mathrm{Cl}_{2}\right)(1)+$ dimethylsulphoxide (2) (A) +acetone (2) $\bullet$, + acetonitrile (2) $\bullet$, and +dibutylether (2) at $303.15 \mathrm{~K}$. 
showed a distinct dependence on the functional group following the order sulpho $>$ keto $>$ nitrile $>$ ether. Such type of the particular interactions is likely to be hydrogen bond creation between the hydrogen of ATC and other donor compounds. The values of $\mathrm{H}^{\mathrm{E}}$ obtained are due to the product of the strength of hydrogen bonding and the number of such bonds which are created in the mixture. From the dielectric properties data of acetone and ATC mixtures, Tripathi [3] predicted that a 1: 1 complex forms between the two, while McClellan and Nicksic [7] studied the DMSO + tetrachloroethane system by NMR and concluded a 1: 1 type of complex formation between these two components. The specific interactions between acetone and DMSO with ATC are much stronger than those in the other two systems and, therefore, an $\mathrm{AB}_{2}$ type of complex creation is not predictable in acetonitrile- ATC and butyl ether-ATC mixtures. It is thus logical to suppose that all four systems form effectively 1: 1 complexes in the binary mixtures. The partial molar enthalpies of dibutylether, acetone, DMSO, acetonitrile in Acetylene Tetrachloride are something like the hydrogen bond energies of the complexes [9]. However, ATC is some extent selfassociated and dibutylether, acetone, DMSO, and acetonitrile have tough specific interactions. Three types of interactions are believed to be present when we mix any of these compounds with acetylene tetrachloride: (1) Other molecules dissociate self association of ATC molecules (2) ATC breaks specific interactions of the second compound (3) There is possibility of strong $\mathrm{H}$-bond formation between acetylene tetrachloride and other donor compound.

In this case (1) and (2) interactions are endothermic whereas the $3^{\text {rd }}$ one is an exothermic reaction. Thus it may be concluded that the enthalpy of mixing is thus the total of two +ve contributions (endothermic) and one -ve(exothermic reactions). The enthalpies of $\mathrm{H}$-bonded complexes $(\Delta \mathrm{Hc})$ are therefore obtained as

$$
\Delta H c=\Delta H_{1},-\Delta H_{2},-\Delta H_{3},
$$

where $\Delta H_{1}, \Delta H_{2}$, and $\Delta H_{3}$ are the partial molar enthalpy of the proton acceptor in acetylene tetrachloride, the partial molar enthalpy of the proton acceptor in a nonpolar solvent and the partial molar enthalpy of ATC in a non-polar solvent, respectively. The $\Delta H_{1}, \Delta H_{2}$, and $\Delta$ $H_{3}$ values were obtained by extrapolating the $\Delta H / \mathrm{x}_{1}, \mathrm{x}_{2}$ versus $x_{1}$ curve to zero mole fraction. The data on the enthalpies of mixing used to obtain the $\Delta H_{2}$, and $\Delta H_{3}$, values were taken from the literature [10-13]. The enthalpies of complex formation therefore obtained are given in Table 3. The strength of hydrogen bonded complexes between different proton acceptor groups increases in the order $\mathrm{S}=\mathrm{O}>\mathrm{C}=\mathrm{O}>\mathrm{C} \equiv \mathrm{N}>\mathrm{C}-\mathrm{O}-\mathrm{C}$.

Dibutyl ether has oxygen which is a weak protonacceptor and creates a delicate complex with ATC. Acetonitrile is also a weaker proton acceptor than acetone and thus creates a weaker complex with ATC, whereas acetone forms a stronger complex. This observation is same as given in the literature $[10,14]$.

The acetone-acetylene tetrachloride complex is weaker than the complex DMSO-ATC by about $2.0 \mathrm{~kJ}$ $\mathrm{mol}^{-1}$. If we compare the structure of DMSO and acetone, they are similar. The only difference is that DMSO has $S$ atom whereas acetone $O$ atom. There is a vacant $3 \mathrm{~d}$ orbital which is present in sulphur atom of DMSO in its electronic configuration, thus facilitating the electron delocalization on the nearby carbon atom. Thus the three hydrogen atoms on the methyl groups of

Table 3: The Enthalpies of Complex Formation $(\Delta H c)$ of ATC with Dimethylsulphoxide (2) +Acetone (2), + Acetonitrile (2), and +Dibutylether (2) at $303.15 \mathrm{~K}$

\begin{tabular}{|c|c|c|c|c|}
\hline System & $\Delta \mathrm{H}_{1}$ & $\Delta \mathrm{H}_{2}$ & $\Delta H_{3}$ & $\Delta \boldsymbol{H}$ \\
\hline \hline ATC + DMSO & -13.0 & & -25.0 \\
\hline ATC + acetone & -9.0 & & -23.0 \\
\hline ATC + acetonitrile & -3.5 & - & -20.8 \\
\hline ATC + dibutylether & -2.8 & 0.9 & -8.7 \\
\hline Dibutylether + hexane & & & 5.0 & \\
\hline ATC + hexane & & 12.3 & & \\
\hline Acetonitrile + hexane & & 9.0 & & \\
\hline Acetone + hexane & & 7.0 & & \\
\hline Dimethy lbenzene + DMSO & & & \\
\hline
\end{tabular}


DMSO are believed to be more acidic than those of acetone [15]. The complex formation between DMSO and ATC are therefore believed to be stronger than those between ATC - acetone, which add to the higher negative values of excess enthalpy in the DMSO-ATC system.

The values of $\mathrm{H}^{\mathrm{E}}$ are exothermic for the system ATC-dibutyl ether, $\approx-1025 \mathrm{~J}^{\mathrm{mol}}{ }^{-1}$ at the minimum indicating only weak interaction between these components. This is due to the creation of weak hydrogen bond between the hydrogen atom of ATC and the donor $\mathrm{O}$ of ether or through $\mathrm{O}---\mathrm{H}$ interactions. The values of excess enthalpy for Acetonitrile-ATC are more negative suggesting stronger complex formation with ATC in the liquid state. The high negative values of dimethylsulfoxide $\left(\approx-3300 \mathrm{~J} \cdot \mathrm{mol}^{-1}\right)$ at the minimum point toward the presence of strong specific interaction leading to the creation of complexes. This can be believed to be due to presence of strong hydrogen bonding between lone pair electrons which are present on the oxygen atom and a hydrogen atom of acetylene tetrachloride as is suggested by Tripathi [1] between dibromomethane and acetone.

\section{ACKNOWLEDGEMENT}

The author is extremely grateful to Professor A.K. Jain, Principal, College of Engineering, Teerthankar Mahaveer University, Moradabad-244001 (India), for his consistent co-operation and encouragement during these investigations.

\section{REFERENCES}

[1] Tripathi AD. Excess Enthalpies of dibromomethane with acetone, 1, 4-dioxane, pyridine, diethyl ether, ethyl methyl ketone, and tetrahydrofuran at $303.15 \mathrm{~K}$. J Chem Eng Data 2010; 55: 1113-6.

http://dx.doi.org/10.1021/je900547w

[2] Tripathi AD. Excess molar enthalpies of dibromomethane with benzene, methanol, dimethylsulfoxide and pyrrolidin-2one at $303.15 \mathrm{~K}$. J Chem Eng Data 2010; 55: 1421-3. http://dx.doi.org/10.1021/je9005882
[3] Tripathi AD. Dielectric properties of mixtures of acetylene tetrachloride with toluene and acetone. J Sol Chem 1994; 23 : 769-76.

http://dx.doi.org/10.1007/BF00972671

[4] Tripathi AD, Chadha R. The excess molar enthalpies of mixing of 1, 1, 2, 2-tetrachloroethane with methylfuran, Tetrahydrofuran, 1,4-dioxane, and cyclopentanone at 308.15 and 318.15 K. J Chem Eng Data 1995; 40: 645-6. http://dx.doi.org/10.1021/je00022a025

[5] Pathak G, Tripathi AD, Phalgune UD, Pradhan SD. Enthalpies of mixing of tetrachloroethane with furan methylfuran, tetrahydro-furan, cyclopentanone and 1,4,dioxane. Thermochim Acta 1995; 258: 109-15. http://dx.doi.org/10.1016/0040-6031(94)02236-H

[6] Tripathi AD. The excess molar enthalpies of 1,1,2,2tetrachloroethane with acetone, dibutyl ether, acetonitrile, and dimethyl-sulfoxide at 298.15 K. J Chem Eng Data 1995; 40: $1262-3$.

http://dx.doi.org/10.1021/je00022a025

[7] McClellan AL, Nicksic SW. Simultaneous, independent hydrogen-bonding equilibria and self association in some halomethanes and haloethanes. J Phys Chem 1965; 69: 446-9.

http://dx.doi.org/10.1021/j100886a014

[8] Mehta SK, Chauhan RK, Tripathi AD. Excess molar enthalpies of mixtures of pyrrolidin-2-one with lower alkanols at the temperature $303.15 \mathrm{~K}$. J Chem Thermodyn 1997; 29: 353-8.

http://dx.doi.org/10.1006/jcht.1996.0163

[9] Van Ness HC, Soczek CA, Kochar NK. Thermodynamic excess properties for ethanol-n-heptane. J Chem Eng Data 1967; 12: 346-51.

http://dx.doi.org/10.1021/je60034a015

[10] Pathak G, Pradhan SD. Enthalpies of mixing of di-n-butyl ether with isomeric butanols. Proc Indian Acad Sci Chem Sci 1988; 100: 519-23.

[11] Murakami S, Fugishiro R. the heats of mixing for binary mixtures. III. The intermolecular energy of hydrogen bonding between alcohol and several other polar molecules. Bull Chem Soc Jpn 1966; 39: 720-5.

http://dx.doi.org/10.1246/bcsj.39.720

[12] Pardo J, Perez P, Royo FM, Gracia M, Losa CG, Gracia M. $H_{\mathrm{m}}{ }^{\mathrm{E}}, V_{\mathrm{m}}{ }^{\mathrm{E}}$, and $\mathrm{G}_{\mathrm{m}}{ }^{\mathrm{E}}$ of $\left\{x \mathrm{Xl}_{2} \mathrm{HCCHCl}_{2}+(1-x) \mathrm{C}_{6} \mathrm{H}_{14}\right\}$ at several temperatures. J Chem Thermodyn 1987; 19: 521-6. http://dx.doi.org/10.1016/0021-9614(87)90148-0

[13] Absood AH, Tutunji MS, Hsu KY, Clever HL. The density and enthalpy of mixing of solutions of acetonitrile and of dimethy sulfoxide with several aromatic hydrocarbons. J Chem Eng Data 1976; 21: 304-8.

http://dx.doi.org/10.1021/je60070a019

[14] Pathak G, Pradhan SD. Enthalpies of mixing of acetonitrile with isomeric butanols; enthalpies of hydrogen -bonded complexes. Indian Acad Sci (Chem Sci) 1991; 103: 189-93.

[15] Graham Solomons TW. Organic Chemistry, Wiley, New York 1976. 